\title{
Analysis on the Development of Financing Mode of "Internet Finance +Agricultural Value Chain" in Shaanxi Province
}

\author{
Dou Tingting ${ }^{1, a^{*}}$, Li yan $^{2, b}$, Li zhao ${ }^{3, c}$ \\ ${ }^{1}$ School of Economics and Management of XI'an Mingde Institute of Technology, Xi'an, Shaanxi, China \\ ${ }^{2}$ School of Economics and Management of XI'an Mingde Institute of Technology, Xi'an, Shaanxi, China \\ ${ }^{3}$ School of Economics and Management of XI'an Mingde Institute of Technology, Xi'an, Shaanxi, China \\ $a^{*}$ doutingting369@163.com \\ b1106215324@qq.com \\ c849194291@qq.com
}

\begin{abstract}
Although agricultural value chain financing can effectively solve the financing difficulties of rural enterprises and farmers, it still has some defects, such as low financing efficiency, high cost, information asymmetry, insufficient collateral and so on. In this paper, first of all, based on the comparative analysis, points out the shortage of the existing agricultural value chain financing model in Shanxi Province. Then using the SWOT analysis method, to search an innovative financing model, which can explore the Internet financial into the agricultural value chain financing. Finally, connecting with the domestic and foreign relevant experience for reference, put forward effective policy recommendations to optimize the development of Shaanxi province "Internet financial + agricultural value chain" financing model.
\end{abstract}

Keywords: Internet finance, agricultural value chain financing, Shaanxi Province

\section{陕西省“互联网金融+农业价值链”融资模式发展分析}

\author{
窦婷婷 $1, a^{*}$,李研 $2, \mathrm{~b}$,李昭 $3, \mathrm{c}$ \\ ${ }^{1}$ 西安明德理工学院经济与管理学院, 西安, 陕西, 中国 \\ 2 西安明德理工学院经济与管理学院, 西安, 陕西, 中国 \\ 3 西安明德理工学院经济与管理学院, 西安, 陕西, 中国 \\ $a^{*}$ doutingting_369@163.com \\ b1106215324@qq.com \\ c849194291@qq.com
}

\section{摘要}

农业价值链融资虽能够有效解决农村企业和农户的融资难问题，但仍存在融资效率低、成本高、信息不对称、 抵押品不足等缺陷。本文通过对陕西省现有农业价值链融资模式的比较分析, 指出其存在的不足, 运用 SWOT 分析，探求将互联网金融融入农业价值链融资的创新融资模式，并结合国内外相关经验借鉴，提出优化发展陕 西省“互联网金融+农业价值链”融资模式的政策建议。

关键词: 互联网金融、农业价值链融资、陕西省 


\section{1.文献综述}

关于农业价值链融资的研究, 国内学者起步相对 较晚, 张庆亮 (2014) ${ }^{\mathbf{2} 21}$ 将农业价值链融资分为两 类, 即链外融资和链内融资。其中, 链外融资是从价 值链外部获得融资, 如银行贷款; 而链内融资是依据 价值链本身筹集资金, 如龙头企业提供贷款。近年来, 互联网金融业务兴起，如何将其与农业价值链融资相 结合, 是国内学者的研究热点。张庆亮 (2014) ${ }^{{ }_{2} 1}$ 认 为, 互联网金融能够优化农业价值链融资渠道, 为农 户贷款提供便利。汪雯羽、孙同权 (2020) ${ }^{\mathbf{b}_{3} \mathbf{1}}$ 定义了 互联网农业价值链金融的概念, 认为其主要模式分为 互联网金融企业主导型、龙头企业主导型和传统金融 机构主导型。李建英 (2020) ${ }^{\mathbf{4}}$ 1 从互联网+农业价值 链融合的三个阶段分析了“互联网金融+农业价值链” 融资的融合模式及其运行机制。

可见，国内针对“互联网金融+农业价值链融资” 的研究尚处于起步阶段, 现有研究多以理论为主, 且 着眼于地方省份的研究很少。我国幅员辽阔, 区域发 展程度不同, 本文以陕西省地方为例展开研究, 对弥 补现有研究的不足具有一定的理论和现实意义。

\section{2.互联网金融背景下陕西省农业价值链融资 模式发展现状}

\section{1 主要模式}

农业价值链融资是以龙头企业为核心，以生产农 产品为主线, 结合链条各个环节主体, 将农户、核心 企业、销售商、银行等结成战略结盟, 依据各主体间 的相关交易，提供金融服务的新兴融资模式。这不但 有助于加强农村金融服务, 对农业供给侧结构性改革 也有很强的推动力。目前, 陕西省主要的农业价值链 融资模式有农业园区主导型、龙头企业主导型和政府 主导型三种主要模式。

\subsection{1 以农业园区为基础的“农户+基地+企业+ 银行”的价值链融资模式。}

陕西省国家级现代农业产业园有杨凌示范区、洛 川苹果产业园和眉县产业园, 建设为以规模化种养基 地为基础, 在龙头企业的带动下, “生产+加工+科技” 融合发展的现代农业产业园。其融资模式参照股份公 司, 企业以技术和管理经验入股, 取得标准化生产的 利润; 农民以土地入股, 赚取租金和劳务收入; 银行 提供资金支持, 收取利息; 政府给予监管和调节, 从 而实现收益共享、风险共担。

\subsection{2以龙头企业为主导的“企业+农户+银行” 的产业链融资模式。}

如陕西省的苹果、猕猴桃产业, 就衍生了一批以 龙头企业为主导, 如海生、华圣等, 与农户形成合作 关系，提供生产技术和资金，并负责收购农产品; 同
时与龙头企业有长期合作关系的银行为农户和企业 提供贷款, 从而达到三方共赢的局面。

\subsection{3 政府为主导的“政府 + 担保机构 + 农村合 作社+银行”的产业链融资模式。}

如杨凌地区的农业产业链融资，政府规划农业用 地, 吸引农业企业入驻, 同时协调金融机构搭建融资 平台, 并提供一定担保, 为当地农业生产助力。

\section{2 存在的问题}

\subsection{1 龙头企业规模较小, 融资能力有限。}

从上述的产业链融资模式中可见, 龙头企业的地 位举足轻重。但陕西省的龙头企业数量较少, 截至 2016年, 农业产业化龙头企业总数只有 2680 家。且他 们其中的绝大部分成立时间较短, 规模小, 实力不强。 因此这也成为制约当地产业链融资发展的重要因素 之一。

\subsection{2 缺乏法律法规等制度。}

虽然近年来陕西不断推出有利于农业产业化发 展的政策制度，但我国现有的法律制度却对农村土地 流转的规范和界定十分模糊, 且土地产权不明、土地 评估机制缺乏等现象也是比比皆是。这些都为农业产 业链融资带来了十分的制度阻碍。

\subsection{3 融资中信用风险严重。}

上述农业价值链融资模式中，主要的资金提供者 是传统金融机构银行, 银行为了控制信贷风险通常会 通过信用评估的方式来降低其风险暴露的可能性, 但 农业价值链上节点很多, 对每个节点上的个体进行详 尽的风险评估会让银行承担很大的贷款成本。且农民 缺乏风险意识, 风险承受能力也较低等。这些都会使 银行遭遇信息不对称，面临严重的信用风险。

\subsection{4 融资效率低、成本高。}

上述农业价值链融资通常需要向银行提供抵押, 而农户和中小农企实力有限，提供抵押能力不足，这 就使得在融资中银行必须要花费大成本进行信用评 估, 筹资方有时不得不以更高的利息成本进行资金借 贷。

综上，虽然农业价值链融资创新了金融融资的渠 道, 在陕西省内也取得了一定的成效, 但仍存在融资 效率低、成本高、信息不对称、抵押品不足等缺点。 而互联网金融的发展为解决这些缺点提供了可靠的 途径, 将互联网金融和农业价值链融资进行有效融合, 能够从根本上解决上述缺点, 实现农业产业资金流、 信息流和物流的统一结合, 使农业价值链增值, 实现 农业规模化生产。 


\section{3.陕西省发展“互联网金融+农业价值链”融资 模式的 SWOT 分析}

\section{1 优势}

3.1.1“互联网金融+农业价值链”融资模式能 够有效解决陕西省农业价值链融资中的不足, 体现普惠金融的特点。

首先，有利于节约融资成本、提高融资效率。农 业价值链融资中因信用风险、缺乏抵押等问题往往会 导致融资失败、融资成本过高等问题。首先, 互联网 大数据技术的运用, 可以有效降低传统银行征信业务 中的成本; 其次, 互联网拥有最高效的贷款流程, 保 证了资金供给的及时性, 从而最大限度地保护农业生 产的时令性特征。

其次，有利于帮助市场增强信用风险管理。一方 面, 农业价值链融资中银行通常会暴露在较大的信用 风险中，而互联网金融可以方便搜集农业借贷数据， 从而规避信用风险。另一方面, 农产品价格随季节的 波动较大, 传统基于订单的农业价值链融资不能有效 避免该风险, 引入互联网机制后, 可以根据以往数据 推测出价格风险的大小, 有助于资金借贷者合理安排 资金使用期限。

最后, 传统农业生产往往会因其蕴含的较高风险 而难以享受现代金融业务所带来的便利和好处, 而互 联网金融的普惠性特征, 将在和农业价值链融资的过 程中很好地呈现出来。首先, 农业企业可以在互联网 金融平台上，根据其在价值链中的地位获得一定的资 金支持; 其次, 农业价值链通常是由多个节点机构所 构成，如金融、支付、保险等，它们之间的业务门监 使得在提供连贯的价值链融资服务时产生阻碍, 而互 联网金融的融入, 可以有效化解这些阻碍, 实现价值 链多方共赢; 最后, 农业价值链能够在互联网金融的 影响下不断增值, 促使农业价值链反哺金融机构, 即 普惠共赢。

\subsection{2“互联网金融+农业价值链”融资模式为 农业规模化发展创造条件。}

我国农业发展的根本出路在于规模化生产。近年 来, 陕西省亦着力培育各类新型农业生产经营主体, 家庭农场、农业企业大量涌现。截至2016年末, 全省 以农业生产经营服务为主的合作社达到 2.39 万个。在 规模化生产中, 自动机械设备的购置、新兴技术的引 进、养殖规模的扩大等都需要大量资金投入，互联网 金融+农业价值链的融资模式以其高效率、低成本的 特点成为支撑农业规模化发展融资需求的重要选择 之一。

\section{2 劣势}

\section{2 .1 省内提供农业价值链融资的金融机构不 多}

首先，陕西省内现有的电商平台主要以农产品交 易业务为主, 涉及农业价值链融资的方面较少; 其次, 大型电商如阿里巴巴、京东, 虽有利用价值链融资的 形式, 但尚处于起步阶段, 缺乏成熟的定式。

\subsection{2 省内农业价值链构成较为薄弱}

虽然陕西省内现有的农业产业园规模居全国前 列, 但农业价值链构成中仍存在薄弱环节。首先, 物 流方面, 物流冷链技术水平较低、运输产能不足; 其 次, 近年来陕西农业虽着力打造陕西特色农产品品牌, 但广为人知的无外乎苹果、猕猴桃、茶叶、秦川牛肉 零胗几个, 且没有对农产品的深加工, 致使农产品附 加值较低; 最后, 在基于农业价值链融资时, 多是以 订单为依托, 这虽可以降低信用风险, 但不能完全消 除农产品的价格风险。且这种融资模式需要政府、银 行、保险公司通力合作才能完成, 因此在省内构建完 善的互联网金融+农业价值链融资模式尚存在较大阻 碍。

\section{3 机遇}

\subsection{1 陕西省农村经济的快速发展为农业价值 链融资奠定了坚实的现实基础}

陕西省位于我国西部地区, 金融服务较沿海发达 城市较为落后。但近年来, 陕西地区经济发展迅速, 2017 年GDP较上年增长 $8 \%$, 人均收入增幅为 $8.3 \%$ 。经 济的快速增长使得农业产业化经营拥有了良好的背 景。同时, 陕西省也是一个农业大省, 2016年, 农林 牧渔总产值为 2985 亿元，其中农业总产值为 2027 亿元， 林业占比 $5 \%$, 畜牧业占比 $34 \%$, 渔业占比 $1.2 \%$ 。这与 2010年的数据相比, 陕西省无论是数量规模还是内部 结构, 均发生了不同程度的优化调整。

\subsection{2 陕西省农业产业化发展较快}

陕西省在2018年1月下发了《关于促进农业产业 化联合体发展的实施意见》, 强调要“创新农业经营方 式, 促进农业产业化发展, 延伸产业链、提升价值链、 拓宽增收链、构建生态链”。为进一步实施农业产业化 组织奠定了坚实的政策基础。其实早在1995年，陕西 省就开始有计划地推动农业产业化经营了。2017年, 陕西省国家级现代农业产业园已有3个，2016年，省 级农业产业园数达336家, 在全国位居第一方阵。农 业价值链融资与农业产业化是密不可分的, 显然, 陕 
西省在产业园建设方面已达到全国先进的行列。

\subsection{3 陕西省农村电子商务发展迅速}

随着互联网的发展和普及, 我国农村网络基础设 施不断完善, 农村网民大幅增加, 截至2019年6月我 国农村网民规模达 2.25 亿, 占全国网民26.3\%。以此为 基础的农村电子商务也呈现出蓬勃发展的态势。到目 前, 陕西省内专门从事农产品贸易的网站就超过了 400 家。如陕西农产品交易网、陕西土特产网等。加之 一些大型企业推行的“电商进农村”活动、自2018年开 始实施的“各十百千万”工程等, 都使得陕西农村电商 发展迅速, 而电商的发展也进一步推动了省内农业价 值链的完善, 这也为“互联网金融+农业价值链”融资 模式的形成奠定了一定的平台基础。

\section{4 挑战}

3.4 .1 省内农业发展仍以小农经济为主, 农民如 何参与“互联网金融十农业价值链”融资仍需 探索。

陕西省是我国西部地区的重要省份之一, 也是一 个农业大省, 但农业整体仍处于小农经济的状态, 传 统金融渗透和下沉尚且不足，供应链的发展相对滞后， 尚未形成规模化农业生产。农民和小型农企在融资时, 抵押品不足, 抗风险能力低, 传统商业银行在进行价 值链融资时多偏向价值链中的龙头企业, 缺乏针对小 农户的资金支持。

3.4.2 陕西省经济布局不均衡, 先进经验难以在 全省适用，如何将“互联网金融十农业价值链” 融资模式覆盖全省有待探索。

陕西省的地理位置决定了其贯穿南北的重要地 位。南方市县经济较为发达, 而靠近西北地区的市县 经济相对落后, 这为先进经验的全省普及带来了一定 阻碍。但不可否认的是, 陕西省农业产业园区建设居 全国前列, 产业园区的建立使得农业产业化融资经验 的普及成为可能。因此对此所带来的挑战笔者还是呈 乐观态度。

\section{4.国内外经验借鉴}

\section{1 国内“互联网金融+农业价值链”融资的先 进经验}

我国“互联网金融+农业价值链”融资正处于起步 阶段, 国内现有的主要模式有三种: 龙头企业+电商, 如蚂蚁金服、京农贷等; 龙头企业自建互联网金融平 台, 如希望金融等; 与传统金融机构合作, 如农村P2P 金融业务、PPP土地模式等。

以蚂蚁金服为例, 农业价值链中的龙头企业依仗 对本行业的深入了解, 将价值链中对资金有需求的企 业推荐给阿里巴巴，阿里巴巴根据龙头企业提供的资 金使用期限、规模、周期等信息，联合金融机构，如 保险公司等，制作出具有针对性的金融创新工具，再 由蚂蚁金服审核后发放给需要的农户和农企, 农户和 农企获得资金后通过淘宝平台向指定供货商购买所 需生产资料。在此过程中，资金用途被严格规范于淘 宝平台购买指定生产资料; 淘宝平台获取农户生产信 息反馈给供货商; 保险公司进行专业风险调查; 网商 银行负责审核发放贷款。可见，通过阿里巴巴和龙头 企业的深度合作，实现贷款资金的闭环管理，即及时 高效地满足了农户生产的资金需求，又实现了信贷风 险的有效控制。

\section{2 国外 “互联网金融十农业价值链”融资的先 进经验}

以美国为例，美国现有农业以规模化生产为主， 其主要的融资模式是通过构建政府政策性金融平台， 实现互联网金融在农业价值链融资中的运用。例如美 国政府设立的农业信贷系统，它包括联邦信贷银行、 农村生产信贷协会等, 利用互联网技术共同为农户提 供资金支持。

综上，关于“互联网金融+农业价值链”融资模式， 国内更多是和大型互联网金融机构合作进行，而国外 主要以政府主导型为主，陕西省在这两种模式中均处 于探索阶段。

\section{5.结论及政策建议}

\section{1 大力发展龙头企业}

一方面, 政府应加大龙头企业的批设力度; 另一 方面, 对一些重要产业的龙头企业，可以给予相关政 
策的优惠。此外, 龙头企业自身也应该在发展本来业 务的同时, 进行企业潜力的深入挖掘, 形成真正具有 较强带动能力的核心大企业。

\section{2 设计完善的风控体制}

价值链生产是未来农业生产的方向，因此产业链 融资还有很大的发展空间。银行可以针对产业链的特 点, 指定一套即行之有效又能节约成本的信用评估体 系, 从而加大对与核心企业、农户乃至每个节点上主 体的风信控制。此外, 政府也可以在当前征信体系下, 为农业产业链融资征信提供帮助。

\section{3 完善相关法规制度}

农业产业链融资面临较多的政策问题, 且陕西省 目前的农业产业链融资还是很依赖政府的扶持。因此 政府相关部门应加强和完善相关法律法规, 使农业合 作组织更加标准和规范。

\section{4 构建地方农业电商平台}

“互联网+”是近年来发展十分迅猛的主题之一, 且国内已经有一些地区有了“互联网+农业”的成功融 资经验, 而陕西省在这一块基本处于空白, 因此顺应 科技和时代的发展, 构建电商平台, 将互联网概念注 入已有的农业产业链融资模式中, 将会为当地的农业 发展注入新的活力。

\section{基金项目}

本文为陕西省教育厅专项科研计划项目《陕西省 “互联网金融+农业价值链”融资模式研究》（编号: 19JK0867）的阶段性成果之一。

\section{REFERENCES}

[1] Bai ma yong zhen.(2016) Study on financing mode of agricultural industry chain in Shaanxi province.J. Business Economics Research.

[2] Zhang qingliang.(2014) Agricultural value chain financing: a new exploration to solve the difficulty of agricultural financing.J. Finance research.

[3] Wang wenyu,Sun tongquan.(2019) Financial Model Analysis of Internet Agricultural Value Chain. J . Research on Rural Finance.

[4] Li jianying, $\mathrm{Wu}$ yanan. The integration mode, operation mechanism and effect of "Internet +" agricultural value chain financing.J. Southwest of financial.

[5] Wang zhengang,Jiangguanghui. Research on the Innovative Mode of "Agricultural Value Chain + Internet Finance". J. Research on Rural Finance. 